\title{
Editorial
}

\section{Pressures on krill}

S pare a thought for the Southern Ocean's krill. Not only is it the staple food of many of the vertebrates in the region but, in a world increasingly concerned about food security and an apparently unstoppable population growth, it is increasingly seen as the unexploited bonanza at the end of the world for humans to harvest.

Commercial krill fishing began about 40 years ago when the Soviet Union and Japan worked out how to remove the chitinous exoskeleton with its toxic fluoride and process the meat for human and animal consumption before autolysis degraded the proteins. There were no controls on harvesting until the Convention for the Conservation of Antarctic Marine Living Resources (CCAMLR) came into being in 1982. Research has continued to develop a more robust estimate of total stock and annual production, information on the krill life cycle and demographics, and the amounts required as food by dependent species. Despite this, the current best production estimate at 342-536 million tonnes per year is still very broad. Using biomass estimates, CCAMLR has been setting area quotas for krill catches since 1993. Whilst in the 1980s up to 500000 tonnes of krill was caught annually this dropped during the late 1980s and 1990s until by the millennium it had stabilised at around 100000 tonnes. By 2008 it had begun to increase again and is now typically just over 200000 tonnes.

Over this period, krill fishing has become more efficient with new trawlers and catching gear, and the market for krill products has diversified, especially with the development of krill oil for its omega-3 health properties, and an increasing number of patents suggests that other uses will soon be developed. Demand for food for fish farms is increasing as is the diversity of medical uses, both likely to drive prices up. Now the pressures on krill are likely to increase significantly with the proposal from China that it will increase its krill fishing fleet substantially. The chairman of the China National Agricultural Development Group has recently suggested that the Southern Ocean could provide up to 100 million tonnes of krill products annually and that China should be aiming at harvesting one to two million tonnes of this.

There have been a variety of claims from many NGOs that this will endanger the entire Southern Ocean ecosystem, and that the present control mechanisms through CCAMLR will not function properly. Yet over two years ago Dr David Agnew at the Marine Stewardship Council noted that the present catches were nowhere near the limits set by CCAMLR, not least because of the extensive dispersal of much krill. The open ocean fishing which would be required to increase catches to even $1 \%$ of the total biomass was simply too expensive. What he did not say was that, as in the old Soviet Union, China subsidies its fishing activities so that the "not economically viable" test may not be an appropriate limitation for a Central Committee objective based on food security.

The all-important sea ice cover in winter is decreasing in the krill hatching area of the Amundsen Sea, the upper levels of parts of the Southern Ocean are warming and acidification of the Southern Ocean from the solution of excess carbon dioxide is slowly progressing. Add further pressures from technology improvements, a wider use of krill products and an exploitation drive by economically powerful countries like China and South Korea. Whilst CCAMLR will undoubtedly continue to try to manage the stock sustainably, the prospects for krill in the next few decades do not look promising - unless you are a fisherman.

D.W.H. WALTON 